\title{
Impact of Climate Change in Indian Agriculture: Special Emphasis to Soybean (Glycine Max (L.) Merr.)
}

\author{
Billy Cherian and VK Khanna* \\ School of Crop Improvement, CPGS, CAU, Meghalaya, India
}

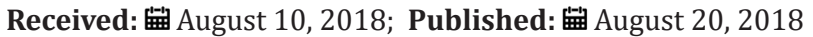

*Corresponding author: VK Khanna, School of Crop Improvement, CPGS, CAU, Barapani, Meghalaya

\section{Introduction}

The impact of climate change on agriculture will be one of the major deciding factors influencing the future food security of mankind on earth. Agriculture is not only sensitive to climate change but, at the same time, is one of the major drivers for climate change. Understanding the weather changes over a period of time and adjusting the management practices towards achieving better harvest is a challenge to the growth of agricultural sector as a whole. The most imminent climatic changes in recent times is the increase in the atmospheric temperatures due to increased levels of greenhouse gases such as carbon dioxide $\left(\mathrm{CO}_{2}\right)$, methane $\left(\mathrm{CH}_{4}\right)$, ozone $\left(\mathrm{O}_{3}\right)$, nitrous oxide $\left(\mathrm{N}_{2} \mathrm{O}\right)$ and chloro fluoro carbons ( $\mathrm{CFCs}$ ). Because of the increasing concentrations of those radiative or greenhouse gases, there is much concern about future changes in our climate and direct or indirect effect on agriculture Garg et al [1]; IPCC [2]; Krupa [3]; Aggarwal [4]. In India, studies by several authors have shown that during the last century there is observed increasing trend in surface temperature Hingane et al. [5]; Srivastava et al. [6]; Pant et al. [7]; Singh et al., 2001, no significant trend in rainfall on all India basis Pant et al. [7]; Mooley and Parthasarathy [8]; Thapliyal and Kulshrestha [9]; Pant and Rupakumar [10]; Stephenson et al. [11], and decreasing/ increasing trends in rainfall on regional basis. In recent years, with the growing recognition of the possibility of global climate change, an increasing emphasis on world food security in general and its regional impacts in particular have come to the forefront of the scientific community.

Crop growth, development, water use and yield under normal conditions are largely determined by weather during the growing season. Even with minor deviations from the normal weather, the efficiency of extremely applied inputs and food production is seriously impaired. The carbon dioxide $\left(\mathrm{CO}_{2}\right)$ concentration was in the steady state at $280 \mathrm{ppm}$ till the pre-industrial period (1850). It is rising since then at the rate of 1.5 to $1.8 \mathrm{ppm}$ per year. The concentration of $\mathrm{CO}_{2}$ is likely to be doubled by the end of $21^{\text {st }}$ century Keeling et al. [12]. Open top chambers and FACE technology are currently being used for the study of the response of crop plants to the elevated $\mathrm{CO}_{2}$. Results from such studies have shown an increase in plant photosynthetic rate and crop yield Kimball [13]. The increased net photosynthetic rate and greater accumulation of sugar contributed significantly to the accelerated development of leaves and tillers and finally grain yield. The increasing $\mathrm{CO}_{2}$ concentration in the atmosphere and the anticipated climate change due to global warming are likely to affect future global agricultural production through changes in rate of plant growth Lemon [14]; Cure and Acock [15]; Rotter and Van de Geijn [16] and transpiration rate Morison [17]; McNaughton and Jarvis [18]; Jacobs and De Bruin 1992. Agriculture plays a key role in overall economic and social well-being of India. Though the share of agriculture in both Gross Domestic Product (GDP) and employment has declined over time, the pace of decline in its share in employment has been much slower than that of GDP. The share of agriculture in GDP is declined from 39\% in 1983 to 24\% in 200001 compared with much lower rate of decline in its share in total employment from $63 \%$ to $57 \%$ during the same period. Declines in the share of agriculture in GDP were not commensurate with the fall in dependency in agriculture. Such trends have resulted in fragmentation and decline in the size of land holdings which leads to agronomic inefficiency, a rise in unemployment and a low volume of marketable surplus. These factors could contribute to increase vulnerability to global environmental change Aggarwal et al. [19]. In India, average food consumption at present is 550gm per capita per day whereas the corresponding figures in China and USA are $980 \mathrm{gm}$ and $2850 \mathrm{gm}$, respectively. Present annual requirement based on present consumption level (550gm) for the country is about 210 Million Tonnes (Mt), which is almost equal to the current production. While the area under food grain, for instance, fell from 
$126.67 \mathrm{mha}$ to 124.24 mha during the period from $1980-81$ to 2003-04, the production registered an increase from $129.59 \mathrm{Mt}$ to 212 Mt during that period.

The food grain production looked quite impressive in 2003-04, which is more than 4 times the production of $50.82 \mathrm{Mt}$ in 195051 . However, the country faces major challenges to increase its food production to the tune of 300 million tons by 2020 in order to feed its ever-growing population, which is likely to reach 1.30 billion by the year 2020. To meet the demand for food from this increased population, the country's farmers need to produce 50 $\%$ more grain by 2020 Paroda and Kumar [20]. The problem has become acute because urbanization and industrialization have rapidly dwindled the per capita availability of arable land from 0.48 ha in 1950 to 0.15 ha by 2000 and is likely to further reduce to 0.08 ha by 2020 . As against the national average of $40 \%$ of the total cropped area being irrigated, $60 \%$ of the total cropped area is still rainfed and dependent on uncertainties of monsoon. This shows the dependency of Indian agriculture on climate. Moreover, if certain climate change scenarios come to pass, agricultural production in some areas may decrease. There is now a great concern about decline in soil fertility, change in water table, rising salinity, resistance to many pesticides and degradation of irrigation water quality in north-western India Sinha et al. [21]. It is clear that over time more nutrients have been removed than added through the fertilizers, and the farmers have to apply more fertilizers to get the same yield, they were getting with fewer fertilizers 2030 years ago. Climate change will further affect soil conditions. Changes in temperature and in precipitation patterns and amount will influence soil water content, run-off and erosion, salinization, biodiversity, and organic carbon and nitrogen content. The increase in temperature would also leads to increased evapotranspiration. There are two major crop growing seasons in India as for climate point of view. The summer or 'kharif' crop growing season (JuneSeptember) coincides with southwest monsoon. The major 'kharif' crops are rice, maize, sugarcane, cotton, jute, groundnut, soybean and Bajra, etc. Depending on crop duration, 'kharif' crops can be harvested during the autumn (October-November) or winter (December-February) months. The southwest monsoon is critical to the kharif crop, which accounts for more than $50 \%$ of the foodgrain production and $65 \%$ of the oilseeds production in the country. The inter annual monsoon rainfall variability in India leads to largescale droughts and floods, resulting in a major effect on Indian food grain production Parthasarathy and Pant [22]; Parthasarathy et al. [23]; Selvaraju, 2003; Kumar et al. [24] and on the economy of the country Gadgil et al. [25]; Kumar and Parikh 2001. The winter or 'rabi' crop-growing season starts after the summer monsoon, and continues through to the following spring or early summer. Rainfall occurring at the end of the monsoon season provides stored soil moisture and often irrigation water for the rabi crop, which is shown in the post-monsoon season (October-November).
The summer monsoon therefore, is responsible for both kharif and rabi crop production in India. The major 'rabi' crops are wheat, mustard, barley, potato, onion and gram, etc. Global warming may also threaten Indian food security if there is a negative effect on agriculture. Although, the effect of increasing $\mathrm{CO}_{2}$ concentrations will increase the net primary productivity of plants, but climate changes, and the changes in disturbance regimes associated with them, may lead either to increased or decreased net ecosystem productivity. In many tropical and subtropical regions, potential yields are projected to decrease for most projected increases in temperature. The impacts of elevated $\mathrm{CO}_{2}$ should be considered among others, in the context of, (A) changes in air temperature, particularly nocturnal temperature due to increase in $\mathrm{CO}_{2}$ and other trace gases and changes in moisture availability and their effect on vegetative versus reproductive growth; (B) need for more farm resources (e.g. fertilizers); and (C) survival and distribution of pest populations, thus developing a new equilibrium between crops and pests Krupa [3]. Indirectly, there may be considerable effects on land use due to melting of snow, spatial and temporal rainfall variability, availability of irrigation, frequency and intensity of inter- and intraseasonal droughts and floods, soil organic matter transformations, soil erosion, change in pest profiles, decline in arable areas due to submergence of coastal lands, and availability of energy. All these can have tremendous impact on agricultural production and hence, food security of any region Aggarwal [4]. The rising temperatures and carbon dioxide and uncertainties in rainfall associated with global warming may or may not have serious direct and indirect consequences on crop production. It is, therefore, important to have an assessment of the direct and indirect consequences of global warming on different crops especially on cereals contributing to the food security (Gadgil et al. [26], 1999 a, b). Mechanistic crop growth models are now routinely used for assessing the impacts of climate change.

There are several crop models now available for the same crop that can be employed for impact assessment of climate change Mall and Aggarwal [27]. Crop models, in general, integrate current knowledge from various disciplines including agrometeorology, soil physics, soil chemistry, crop physiology, plant breeding, and agronomy, into a set of mathematical equations to predict growth, development and yield of a crop Aggarwal and Kalra [28]; Hoogenboom [29]. In most climate change applications, long-term historical weather data are used as input for the crop models. In general, at least 30 years of historical weather data are preferred to represent annual weather variability; different climate change scenarios can then be applied to these data records. The simplest approach is to assume a fixed climate change and to modify the data with a constant number, such as an increase or decrease of 1, 2, 30C, etc. for temperature. Similarly, rainfall and solar radiation can be changed with a certain percentage, such as an increase or decrease of $10,20,30 \%$, etc. These changes are then applied to the daily water 
data and the crop simulation models are run with these modified inputs. A more realistic approach is to use the outputs from the General Circulation Models (GCMs) to modify the historical weather data Hoogenboom [29]; Lal et al. [30]; Mall et al. [31]. Crops that utilize the C3 photosynthetic pathway including many staple foods such as wheat, soy and rice are expected to benefit from increasing atmospheric $\mathrm{CO}_{2}$ concentrations. These benefits could offset the challenges posed by increases in the occurrence and severity of climatic stressors, such as heat and drought. In particular, plants are expected to experience stimulation of photosynthesis that will directly increase yield, and reduced stomatal conductance that will lower water use and thereby ameliorate drought stress. However, tests of these ideas in crop field trials are limited to relatively cool and wet environments. Sharon Gray from the University of Illinois at Urbana-Champaign, US and co-workers used data from an eight-year open air field experiment where they manipulated precipitation and $\mathrm{CO}_{2}$ concentrations and utilized year-to-year variations in weather conditions to investigate these interacting effects on soybean crops.

In India, soybean research and cultivation had minor contribution before 1965. Exotic lines received from USA were tested by conducting trials at the Jawaharlal Nehru Krishi Vishwa Vidyalaya (JNKVV), Jabalpur and almost concurrently at the Govind Ballabh Pant University of Agriculture and Technology (GBPUA \& T), Pantnagar and suitability of soybean cultivation in India was proved. The encouraging results led to the establishment of All India Coordinated Project in 1967 by ICAR. The breeding objectives were focused on germinability and longevity, resistance to shattering and lodging, early and medium duration, four seeded pods, profuse podding and quality and resistance to biotic and abiotic stresses. So far about 100 improved soybean varieties possessing various traits are available in India by applying hybridization and mutation breeding. Important traits such as drought tolerance, photoperiod insensitivity, resistant to diseases such as rust, charcoal rot, and YMV, resistance to insects such as stem borers and defoliators, and food uses such as vegetable types, high oil content, high oleic acid content, low lipoxygenase content and null Kunitz Trypsin inhibitor were identified. To enhance the efficiency of breeding programmes using molecular tools, the QTLs for high seed longevity and markers for YMV resistance genes were identified. For harnessing the optimum productivity for a rainfed crop optimum phenology for harnessing maximum yield of rainfed soybean in Central India has been worked out.

The effect of increased $\mathrm{CO}_{2}$ treatments on yield was found to diminish to zero as drought intensified. This unexpected result occurred because elevated $\mathrm{CO}_{2}$ interacted with drought to modify stomatal function, canopy energy balance and nitrogen uptake. The outlook for soy production under these interacting global change factors is concerning. Lal et al. (1999) projected $50 \%$ increased yield for soybean for a doubling of $\mathrm{CO}_{2}$ in Central India by using CROPGRO-soybean model. However, a $3^{\circ} \mathrm{C}$ rise in surface air temperature almost cancels out the positive effects of doubling of carbon dioxide concentration resulting in reducing the total duration of the crop (and hence productivity) by inducing early flowering and shortening the grain filling period. Soybean crops in Central India are found to be more vulnerable to increase in maximum temperature than in minimum temperature. A decline in daily rainfall amount by $10 \%$ restricts the grain yield to about $32 \%$. They concluded that acute water stress due to prolonged dry spells during monsoon season could be a critical factor for the soybean productivity even under the positive effects of elevated $\mathrm{CO}_{2}$ in the future.

\section{Future Breeding Objectives}

Change in climatic patterns would compel major realignments in existing cropping pattern and systems. The projected change in climate may lead to emergence of new insect pests and diseases which assume menacing proportion and large segment of agricultural area could be under abiotic stresses. An increase in the number of outbreaks of a wider variety of insects, nematodes and pathogens and increased damage potential of existing and invasive pests and diseases is anticipated. To address these constrains of productivity, following strategies need to be followed.

\section{Conventional Breeding Approaches}

Breeding based on yield components: Soybean breeders have to be ready with necessary realignments to make crop extremely resilient to weather and climatic fluctuations and extremities. There is no alternative to conventional breeding but this needs reorientation or revamping. Yield potential may be built up by progressive assembling of positive genes including productivity, quality, resistance to biotic and abiotic stresses, simultaneously. Soybean cultures having profuse podding crossed with fourseeded pod cultures may produce genotypes combining these two desirable characters and substantial yield increase can be achieved Shrivastava [32]. Hybridization programmes should be performed taking cultures having multiple attributes with multiple resistances for the future sustainability of varieties rather than improving a single trait. Mutation breeding may also have a place in breeding to create new variability for targeted traits. Breeding based on physiological traits: It is imperative to consider yield components along with physiological characters simultaneously for substantial genetic gain in yield. The characters such as earliness, faster growth rates, photo-insensitivity and appropriate biomass, assimilate supply during seed filling period with high harvest index, per day productivity, high leaf photosynthesis, specific leaf weight, and these have been identified as important traits to be incorporated in future breeding programmes Bhatia et al. [33]. Identification of morphological and biochemical traits for drought, high temperature and excessive moisture tolerance and their use in breeding programme is required. 
a) Breeding for Biotic Stresses: Soybean diseases such as rust, yellow mosaic, charcoal root rot, Rhizoctonia aerial blight, rust, Rhizoctonia solani rot, etc. are collectively causing significant yield losses in soybean. Fortunately, sources of genic resistance for YMV are available in adapted genetic background that have 'PI 171443' (UPSM 534) in their pedigree as their main source Singh et al., 1974 a, b; Ram et al. [34]. Screening and breeding work has to be intensified to combat future menace. In the predominant soybean growing area, green semi-loopers, tobacco caterpillar, Bihar hairy caterpillar, girdle beetle, stem fly and whitefly are the major insect-pests of great concern. Breeding for insect-pests resistance is now receiving the impetus.

b) Resistance for Abiotic Stress: Soybean suffers from drought and also excess water conditions. For improved and stable yields, it would be desirable to develop soybean varieties to cope with drought and excess water stresses prevalent in target environments. In India, soybean cultivars have not been specifically developed for drought and excess moisture stress conditions although tolerance in some lines is reported for these. Variety 'JS 97-52' has, however, been reported to be tolerant to excessive soil moisture. Systematic efforts are, therefore, needed for identifying sources of tolerance and associated physiological characters. Several morphological, physiological and biochemical characters have been associated with drought resistance in soybean. Sloane et al. (1990) reported that soybean line PI 416937 was less sensitive to drought than currently grown cultivars. The genotype had larger and thicker leaves and was superior in the ability to maintain leaf turgor, transpiration and net $\mathrm{C}$-exchange rates under severe drought stress. Canopy temperature depression, canopy growth and per cent growth cover at early stage (aided by image/ camera, photographic analysis) have also been found useful in several crops. Singh et al. (1973) and Sarkar et al. (1991) suggested some criteria for identification of drought resistance.

c) Molecular Approaches: The identified genetic sources will be used for crop improvement using functional genomics, MAS, transgenic and allele mining approaches. Harnessing hybrid vigour and accumulation of yield, tolerance to drought and excessive moisture related QTLs to overcome genetic yield barriers will provide opportunities to enhance the genetic yield potential of soybean. Soybean breeders would have the challenge of introgressing valuable traits from secondary and tertiary gene pools by utilizing widely available and established tools of modern biotechnology.

Genetically modified soybean would possibly become a norm for effective biotic stress management (weeds, insect pests and diseases) and would widely be acceptable across the globe thus making it imperative for India also to have GM soybean in the country. Researchers would have to be ready with production technologies compatible with GM soybean. Examination of relatively recent weather of the last century at many parts of the country indicates warming trends although statistically these may not be significant, but there are enough indicators to suggest a modest increase in $\mathrm{CO}_{2}$ and temperature. In spite of the uncertainties about the precise magnitude of climate change on regional scales due to scenarios and crop models on impact assessment, an assessment of the possible impacts of climate change on India's agricultural production under varying socio- economic conditions is important for formulating response strategies, which should be practical, affordable and acceptable to farmers. The identification of suitable response strategies is key to sustainable agriculture. The important mitigation and adaptation strategies required to cope with anticipated climate change impacts include adjustment in sowing dates, breeding of plants that are more resilient to variability of climate, and improvement in agronomic practices. The results obtained by Mall et al. [31] on the mitigatory option for reducing the negative impacts of temperature increases indicate that delaying the sowing dates would be favorable for increased soybean yields at all the locations in India. Sowing in the second season would also be able to mitigate the detrimental effects of future increases in surface temperature due to global warming at some locations. However, the proposed shift in soybean production from the current main season to a second season may necessitate additional planning and change in management practices. There is need to identify district or agro-climatic regions vulnerable to climate change and identify suitable adaptation practices to be followed in order to sustain the productivity of these regions to some extent. These adaptation strategies may include altered crops and cropping systems to maintain soil fertility in sustainable manner and improved management practices. Modern technologies in agriculture could also be beneficial with or without climate change; government should encourage farmers to shift towards newer technologies. The government should also encourage research on developing crop varieties that can withstand changes in the climate.

Several studies projected increase or decrease in yields of cereal crops (rice, wheat, maize and sorghum), oilseed and pulses crops (soybean, groundnut, chickpea, brassica and pigeon pea) depending on interaction of temperature and $\mathrm{CO}_{2}$ changes, production environment, season and location in India. Still the climate change impact studies have not conducted on several important crops in India such as sugarcane, cotton, jute, sunflower, potato and onion, etc. which may be done in future for better assessment of vulnerability of Indian agriculture due to climate change. However, these studies have indicated that the impacts of climate changes would be small on 'kharif' crops but overall 'kharif' agriculture will become vulnerable due to increased incidence of weather extremes such as onset of monsoon, duration and frequency of drought and floods, and pest incidence and virulence. Production of 'rabi' crop is relatively riskier due to projection of larger 
increase in temperature and higher uncertainties in rainfall. Unless considerable adaptation takes place, this would result in decreased winter or 'rabi' production (Figure 1). An index of sustainability that included economic (agricultural production, income, and risk) and environmental (ground water level, land degradation and biodiversity) indicators clearly shows that the agricultural production is under threat and needs immediate attention Joshi et al. [35]. Although, the effect of climate change on crop productivity could be biased depending upon the uncertainties in crop models used for impact assessment, climate change scenarios, region of study, technological changes and the agronomic management, the integrated assessment of climate change impact on different sectors of Indian economy is very important to determine future strategies for sustainable development, adaptation and other policy decisions [36,37]. It is worthwhile to note that Kumar and Parikh (2001) projected that with $2^{\circ} \mathrm{C}$ increase in temperature and $7 \%$ increase in the precipitation the net-revenue of India will be decline by $8.4 \%$. It is also important that losses expected from the climate change on Indian agriculture will be more [38,39]. This should be due to the warmer temperature that the Indian farmers face under the present climatic conditions and also the relatively low level of management because small and marginal farmers with less land holding are more than $60 \%$ of the total farmers. Such an assessment on agriculture and therefore policy response to manage climate change impacts will not be complete unless the biophysical, environmental and socioeconomic sectors of agro-ecosystems are studied together $[40,41]$.

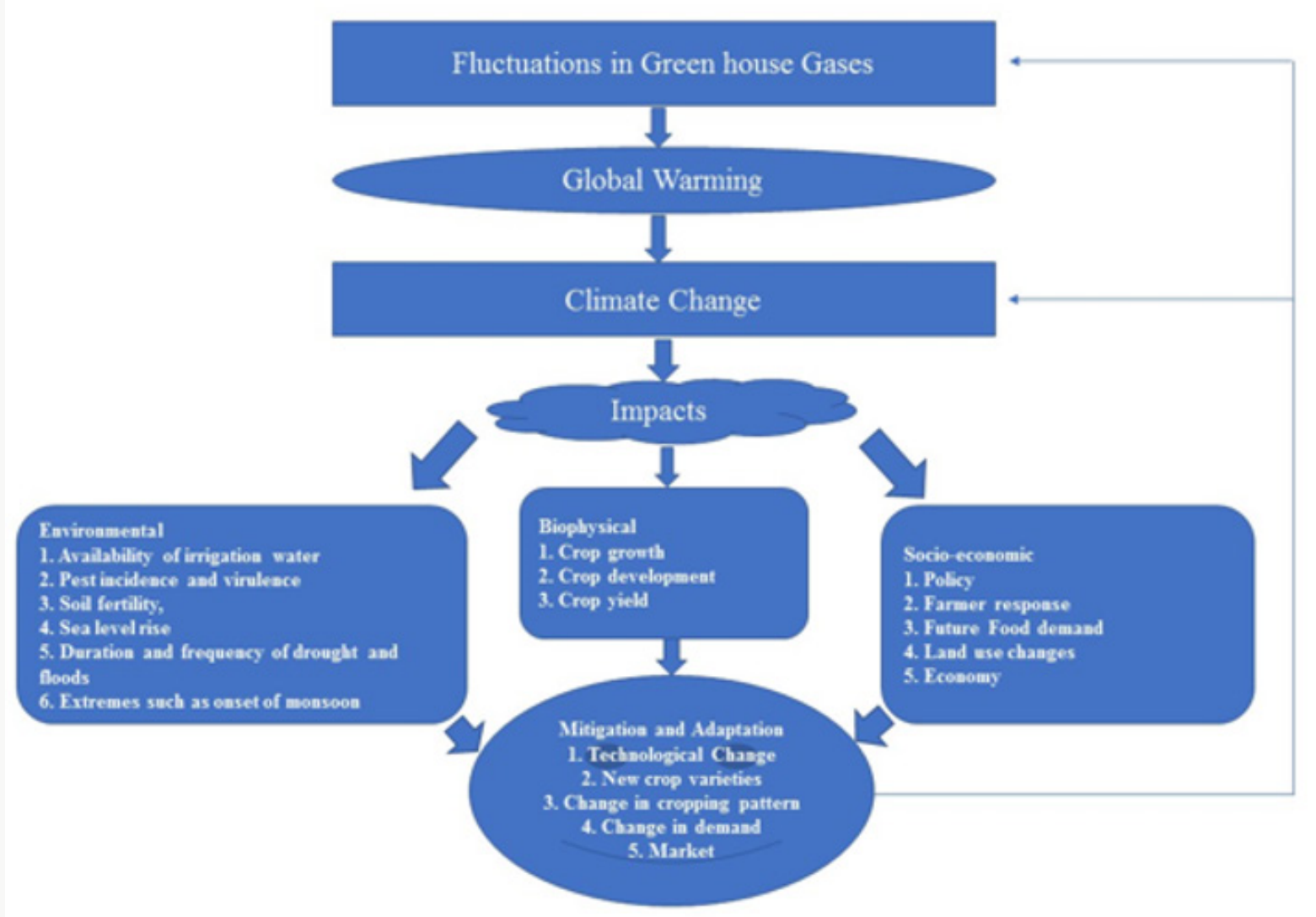

Figure 1: Climate change and mitigation strategies.

Global integrated impact assessment models though provide such a framework but are inadequate for regional policy planning because these are not validated at that scale and due to their inherent inter-and intra-sectoral conflicts $[42,43]$. We need to urgently develop our own integrated assessment simulation models in which cropping systems; water use and socioeconomic parameters need to be brought together for assessing the impact of environmental change in diverse regions of the country $[44,45]$. It may be developed in collaboration with several stakeholders including policy makers, agricultural and environmental scientist, climatologist, economist, administrators, industry and farmer's organization [46].

\section{References}

1. Garg A, Shukla PR, Bhattacharya S. Dadhwal VK (2001) Sub-region (district) and sector level $\mathrm{SO}_{2}$ and $\mathrm{NO}_{2}$ emissions for India: assessment of inventories and mitigation flexibility. Atmospheric Environment 35(4): 703-713.

2. Houghton JT, Y Ding DJ, Griggs M Noguer, PJ van der Linden X IPCC (2001) (Intergovernmental Panel for Climate Change), Climate Change 2001-The Scientific Basis. Contribution of Working Group I to the Third Assessment Report of the Intergovernmental Panel on Climate Change. 
3. Krupa S (2003) Atmosphere and agriculture in the new millennium. Environmental Pollution 126(3): 293-300.

4. Aggarwal PK (2003) Impact of climate change on Indian agriculture. J Plant Biology 30(2): 189-198.

5. Hingane LS, Rupa Kumar K, Ramana Murthy BV (1985) Long-term trends of surface air temperature in India. J Climatol 5(5): 521-528.

6. Srivastava HN, Dewan BN, Dikshit SK, Rao GSP, Singh SS, et al. (1992) Decadal trends in Climate over India. Mausam 43: 7-20.

7. Pant GB, Kumar R, Borgaonkar HP (1999) Climate and its long-term variability over the western Himalaya during the past two centuries. The Himalayan Environment (Eds. S. K. Dash and J. Bahadur), New Age International (P) Limited, Publishers, New Delhi, pp. 172-184.

8. Mooley DA, Parthasarathy B (1984) Fluctuations of All India summer monsoon rainfall during 1871-1978. Climatic Change 6(3): 287-301.

9. Thapliyal V, Kulshrestha SM (1991) Climate changes and trends over India. Mausam 42: 333-338.

10. Pant GB, Rupakumar K (1997) Climates of South Asia, John Wiley \& Sons Ltd.,West Sussex, UK, pp. 320.

11. Stephenson BD, Douville H, Rupakumar K (2001) Searching for a fingerprint of global warming in the Asian summer monsoon. Mausam 52: $213-220$.

12. Keeling CD, Whorf TP, Wahlen MM, Vander Plicht J (1995) Inter-annual extremes in the rate of rise of atmosphric carbon dioxide since 1980 Nature 375(6533): 666-670.

13. Kimball BA (1982) Carbon dioxide and agricultural yield: an assemblage and analysis of 430 prior observations. Agronomy J 75(5): 779-788.

14. Lemon ER (1983) $\mathrm{CO}_{2}$ and plants: The response of plants to rising levels of atmospheric carbon dioxide. West view Press, Boulder, CO., USA.

15. Cure JD, Acock B (1986) Crop responses to carbon dioxide doubling literature survey. Agric Forest Meteorology 38(1-3): 127-145.

16. Rotter R, Van de Geijn SC (1999) Climate change effects on plant growth, crop yield and livestock. Climate Change 43(4): 651-681.

17. Morison JIL (1987) Intercellular $\mathrm{CO}_{2}$ concentration and stomata response to $\mathrm{CO}_{2}$ In: Zeiger, E Cowan, IR Farquhar, GD(Eds.). Stomatal Function. Stanford University Press, USA, pp. 229-251.

18. Mc Naughton KG, Jarvis PG (1991) Effects of spatial rate on stomatal control of transpiration. Agric Forest Meteorology 54(2-4): 279-302.

19. Aggarwal PK, Joshi PK, Ingram JSI, Gupta RK (2004) Adapting food systems of the Indo-Gangetic plains to global environmental change: key information needs to improve policy formulation. Environmental Science \& Policy 7(6): 487-498.

20. Paroda RS, Kumar P (2000) Food production and demand in South Asia. Agricultural Economics Research Review 13(1): 1-24.

21. Sinha SK, Singh GB, Rai M (1998) In: Decline in crop productivity in Haryana and Punjab: myth or reality? Indian Council of Agricultural Research, New Delhi, India p. 89.

22. Parthasarathy B, Pant GB (1985) Seasonal relationship between Indian summer monsoon rainfall and southern oscillation. Journal of Climate 5(4): 369-378.

23. Parthasarathy B, Rupa Kumar K, Munot AA (1992) Forecast of rainy season food grain production based on monsoon rainfall. Indian J of Agric Sci 62: 1-8.

24. Kumar KK, Kumar KR, Ashrit RG, Deshpande NR, Hansen JW (2004) Climate impacts on Indian agriculture. International Journal of Climatology 24(11): 1375-1393.

25. Gadgil S, Rao PR, Sridhar PR (1999) Modeling impact of climate variability on rainfed groundnut. Current Science 76(4): 557-569.
26. Gadgil S (1995) Climate change and Agriculture-An Indian Perspective. Current Science 69(8): 649-659.

27. Mall RK, Aggarwal PK (2002) Climate change and rice yields in diverse agro-environments of India. I. Evaluation of impact assessment models. Climatic Change 52(3): 315-331.

28. Aggarwal PK, Kalra N (1994) Simulating the effect of climatic factors, genotype and management on productivity of wheat in India. Indian Agricultural Research Institute Publication, New Delhi, India pp. 156.

29. Hoogenboom G (2000) Contribution of agrometeorology to the simulation of crop production and its applications. Agric. Forest Meteorology 103: 137-157.

30. Lal M, Singh KK, Srinivasan G, Rathore LS, Saseendran AS (1998) Vulnerability of rice and wheat yields in NW-India to future change in climate. Agric Forest Meteorolog 89(2): 101-114.

31. Mall RK, Lal M, Bhatia VS, Rathore LS, Singh R (2004) Mitigating climate change impact on Soybean productivity in India: A simulation study. Agricultural and Forest Meteorology 121(1-2): 113-125.

32. Shrivastava AN, Shrivastava MK, Manjaiya JG (2011) Significance of fourseeded pod trait in soybean yield improvement. Soybean Research 9 53-61.

33. Bhatia VS, Tiwari SP, Joshi OP (1996) Interrelationship of leaf photosynthesis, specific leaf weight and leaf anatomical characters in soybean. Indian Journal of Plant Physiology, New Series 1(1): 6-9.

34. Ram HH, Pushpendra SK, Verma VD (1981) Breeding soybean varieties for northern India. Soybean Genetics Newsletter 8: 74-8.

35. Joshi PK, Joshi L, Singh RK, Thakur J, Singh K, et al. (2003) Analysis of productivity changes and future sources of growth for sustaining rice-wheat cropping system. NATP Report submitted to the Irrigated Ecosystem. National Centre for Agricultural Economics and Policy Research, New Delhi.

36. Aggarwal PK, Kropff MI, Cassman KG, Ten Berge HFM (1997) Simulating Genetic Strategies for Increased Yield Potential in Irrigated, Tropical Environments. Field Crops Res 51(1-2): 5-17.

37. Aggarwal PK, Mall RK (2002) Climate change and rice yields in diverse agro-environments of India. II. Effect of uncertainties in scenarios and crop models on impact assessment. Climatic Change 52(3): 331-343.

38. Aggarwal PK, Sinha SK (1993) Effect of probable increase in carbon dioxide and temperature on productivity of wheat in India. J of Agric Meteorology 48(5): 811-814

39. Aggarwal PK, Talukdar KK, Mall RK (2000) Potential Yields of Rice-Wheat System in the Indo-Gangetic Plains of India. Rice-Wheat Consortium Paper Series 10, RWCIGP, CIMMYT, New Delhi, p. 16.

40. Aggarwal PK (2000) Application of systems simulation for understanding and increasing yield potential of wheat and rice. $\mathrm{PhD}$ thesis, Wageningen University, The Netherlands, pp. 176.

41. Chowdhury A, Abhyankar VP (1979) Does precipitation pattern foretell Gujrat climate becoming arid? Mausam 30: 85-90.

42. Gadgil S, Abrol YP, Rao Seshagiri PR (1999) On growth and fluctuation of Indian food grain production. Current Science 76(4): 548-556.

43. Kripalani RH, Inamdar SR, Sontakke NA (1996) Rainfall variability over Bangladesh and Nepal: comparison and connection with features over India. International Journal of Climatology 16: 689-703.

44. Sarkar RK, Saini JP, Dubey SD (1999) Testing of soybean genotypes for drought tolerance. Indian Journal of Agricultural Sciences 61: 369-373.

45. Singh N, Sontakke NA (2002) On climatic fluctuations and environmental changes of the Indo-Gangetic plains, India. Climatic Change 52(3): 287313.

46. Sloane RJ, Patterson RP, Carter TE (1988) Field drought tolerance of a soybean plant introduction. Crop Science 30(1): 118-123. 
(C) (P) This work is licensed under Creative

To Submit Your Article Click Here: Submit Article

DOI: $10.32474 /$ OAJOM.2018.02.000141

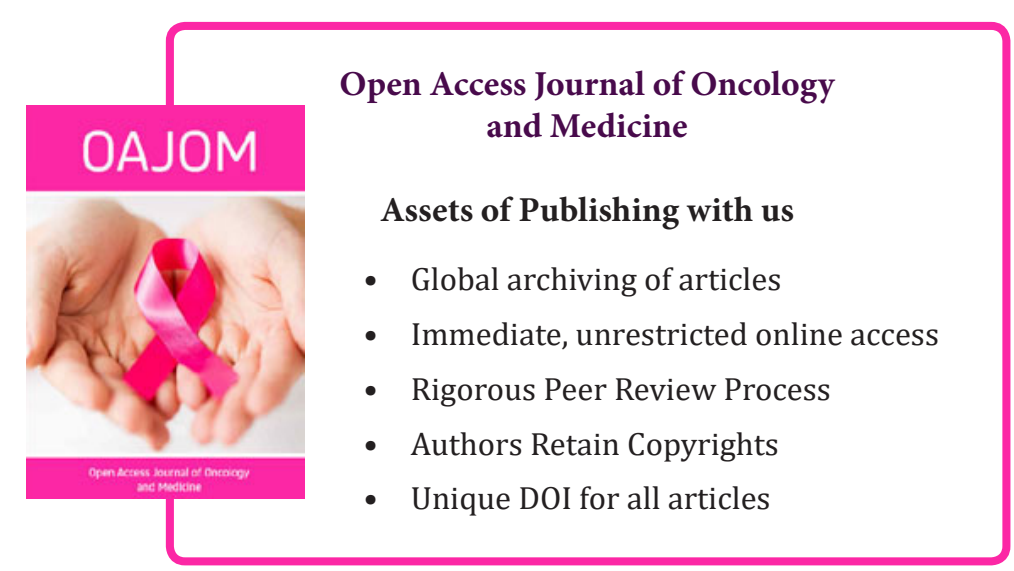

